Article

\title{
Clinical Outcomes in Patients Aged 80 Years or Older Receiving Non-Invasive Respiratory Support for Hypoxemic Acute Respiratory Failure Consequent to COVID-19
}

\author{
Andrea Vianello ${ }^{1} * \mathbb{D}$, Nello De Vita ${ }^{2}$, Lorenza Scotti ${ }^{2}$, Gabriella Guarnieri ${ }^{1}$, Marco Confalonieri ${ }^{3}$ (D), \\ Valeria Bonato $^{4}$, Beatrice Molena ${ }^{1}$, Carlo Maestrone ${ }^{5}$, Gianluca Airoldi ${ }^{6}$, Carlo Olivieri ${ }^{7}$, Pier Paolo Sainaghi ${ }^{2} \mathbb{D}$, \\ Federico Lionello ${ }^{1}$, Giovanna Arcaro ${ }^{1}$, Francesco Della Corte ${ }^{2}$, Paolo Navalesi ${ }^{8,+}$ (D) and Rosanna Vaschetto ${ }^{2,+}$ (iD
}

check for updates

Citation: Vianello, A.; De Vita, N.; Scotti, L.; Guarnieri, G.; Confalonieri, M.; Bonato, V.; Molena, B.; Maestrone,

C.; Airoldi, G.; Olivieri, C.; et al. Clinical Outcomes in Patients Aged 80 Years or Older Receiving Non-Invasive Respiratory Support for Hypoxemic Acute Respiratory Failure Consequent to COVID-19. J. Clin. Med. 2022, 11, 1372. https:// doi.org/10.3390/jcm11051372

Academic Editor:

Jose-Manuel Ramos-Rincon

Received: 10 February 2022

Accepted: 28 February 2022

Published: 2 March 2022

Publisher's Note: MDPI stays neutral with regard to jurisdictional claims in published maps and institutional affiliations.

Copyright: (C) 2022 by the authors. Licensee MDPI, Basel, Switzerland. This article is an open access article distributed under the terms and conditions of the Creative Commons Attribution (CC BY) license (https:// creativecommons.org/licenses/by/ $4.0 /)$
1 Department of Cardiac Thoracic Vascular Sciences and Public Health, University of Padova, Via Gallucci, 13 , 35121 Padova, Italy; gabriella.guarnieri@unipd.it (G.G.); beatrice.molena@unipd.it (B.M.);

federico.lionello@aopd.veneto.it (F.L.); giovanna.arcaro@aopd.veneto.it (G.A.)

2 Dipartimento di Medicina Traslazionale, Università del Piemonte Orientale, Via Solaroli, 17, 28100 Novara, Italy; nellodevita@hotmail.com (N.D.V.); lorenza.scotti@uniupo.it (L.S.); pierpaolo.sainaghi@med.unipmn.it (P.P.S.); francesco.dellacorte@med.uniupo.it (F.D.C.); rosanna.vaschetto@med.uniupo.it (R.V.)

3 Pneumologia, Azienda Sanitaria Universitaria Giuliano Isontina, Via Giacomo Puccini, 50, 34148 Trieste, Italy; marco.confalonieri@asugi.sanita.fvg.it

4 Department of Anesthesia and Intensive Care, Azienda Ospedaliera SS. Antonio e Biagio e Cesare Arrigo, Via Venezia, 16, 15121 Alessandria, Italy; vbonato@ospedale.al.it

5 Anestesia Rianimazione ASL VCO, Dipartimento Chirurgico, Presidio Ospedaliero Domodossola e Verbania, Largo Caduti Lager Nazisti, 1, 28845 Domodossola, Italy; carlo.maestrone@aslvco.it

6 Medicina Interna, Ospedale Ss. Trinità, Viale Zoppis, 10, 28021 Borgomanero, Italy; gianluca.airoldi@asl.novara.it

7 Department of Anesthesia and Critical Care, Azienda Ospedaliera Sant'Andrea, Corso M. Abbiate, 21, 13100 Vercelli, Italy; carlo.olivieri@aslvc.piemonte.it

8 Istituto di Anestesia e Rianimazione, Dipartimento di Medicina-DIMED-Università di Padova, Azienda Ospedale-Università di Padova, Via Gallucci, 13, 35121 Padova, Italy; paolo.navalesi@unipd.it

* Correspondence: andrea.vianello@aopd.veneto.it; Tel.: +39-049-821-8587; Fax: +39-049-821-7791

$+\quad$ These authors contributed equally to this work.

\begin{abstract}
As the clinical outcome of octogenarian patients hospitalised for COVID-19 is very poor, here we assessed the clinical characteristics and outcomes of patients aged 80 year or older hospitalised for COVID-19 receiving non-invasive respiratory support (NIRS). A multicentre, retrospective, observational study was conducted in seven hospitals in Northern Italy. All patients aged $\geq 80$ years with COVID-19 associated hypoxemic acute respiratory failure (hARF) undergoing NIRS between 24 February 2020, and 31 March 2021, were included. Out of 252 study participants, 156 (61.9\%) and $163(64.6 \%)$ died during hospital stay and within 90 days from hospital admission, respectively. In this case, 228 (90.5\%) patients only received NIRS (NIRS group), while 24 (9.5\%) were treated with invasive mechanical ventilation (IMV) after NIRS failure (NIRS+IMV group). In-hospital mortality did not significantly differ between NIRS and NIRS+IMV group ( $61.0 \%$ vs. $70.8 \%$, respectively; $p=0.507)$, while survival probability at 90 days was significantly higher for NIRS compared to NIRS+IMV patients ( 0.379 vs. $0.147 ; p=0.0025)$. The outcome of octogenarian patients with COVID-19 receiving NIRS is quite poor. Caution should be used when considering transition from NIRS to IMV after NIRS failure.
\end{abstract}

Keywords: non-invasive respiratory support; octogenarian patients; COVID-19; acute respiratory failure

\section{Introduction}

Severe acute respiratory syndrome coronavirus 2 (SARS-CoV-2) infection, which causes coronavirus disease 2019 (COVID-19), was declared a global pandemic by the World 
Health Organization (WHO) on 11 March 2020. Disease severity from COVID-19 varies widely, and older adults are more likely to progress to severe disease, leading to high mortality rates [1]. In Italy, patients between 60-69, 80-89, and over 90 years old showed a case fatality rate (CFR) of $3.5 \%, 19.7 \%$, and $22.7 \%$, respectively $[2,3]$. During the first pandemic wave, in-hospital mortality rate in octogenarian COVID-19 patients in the New York City area was about 54\% [4]. In a similar cohort of patients in Spain, the mortality rate was 33.3\% [5]. Of interest, frailty was independently associated with lower survival in a population of 1346 patients with a median age of 75 years admitted to ICUs from 28 countries [6].

During the first pandemic wave, the use of mechanical ventilation (MV) for the management of COVID-19-associated hypoxemic acute respiratory failure (hARF) in older patients resulted in poor clinical outcomes. Indeed, a mortality rate of $72 \%$ was reported in 280 out of 388 subjects older than 80 years $-68 \%$ of whom treated with invasive MV (IMV) - in German hospitals [7]. Adverse outcomes together with increasing concerns about ventilator shortages have led clinicians to consider other approaches to treat COVID19 ARF patients, if medically appropriate, such as the use of non-invasive respiratory support (NIRS) - i.e., continuous positive airway pressure (CPAP) and/or non-invasive positive pressure ventilation (NPPV) [8]. To date, studies on COVID-19 focusing on clinical outcomes in older patients receiving NIRS due to hARF are scarce, showing a mortality rate ranging from $51.6 \%$ in octogenarian subjects receiving CPAP, NPPV, or high flow nasal cannula (HFNC) [9] to 70\% in patients for whom NIRS is the ceiling of care [10-12].

Italy was one of the first European countries affected by COVID-19 and the evidence of age and frailty being associated with mortality was not initially known, particularly in those subjects receiving NIRS.

In our study, we aimed to describe the clinical characteristics and outcomes of patients aged 80 years or more hospitalized for COVID-19-associated hARF receiving NIRS at intermediate respiratory care units (IRCUs).

\section{Methods}

This is a multicentre, retrospective, cohort study based on medical records of three tertiary teaching hospitals (Padua, Novara and Trieste University Hospital) and four hospitals (Alessandria, Borgomanero, Domodossola and Vercelli hospital) in Northern Italy. All medical records of COVID-19 ARF patients aged $\geq 80$ years treated with NIRS at IRCUs between 24 February 2020 and 31 March 2021 were collected and reviewed. The data were anonymised. Participating centres obtained ethics committee approval for the present research project (CE 243/21). Due to the retrospective nature of the study, the ethics committee waived the need for informed consent. This study was performed in accordance with the ethical standards of the 1964 Declaration of Helsinki and its later amendments or comparable ethical standards. Local investigators were responsible for ensuring data integrity and validity.

\subsection{Participants}

We retrospectively evaluated all patients aged $\geq 80$ years diagnosed with severe pneumonia and laboratory confirmed SARS-CoV-2 infection [13] admitted to the IRCU of the participating hospitals for hARF who underwent CPAP or NPPV during the study period.

Hypoxemic ARF was defined as an acute, rapid deterioration in respiratory function and an exacerbation of dyspnoea over a few day time associated with a deterioration in blood gas tensions leading to hypoxemia-arterial oxygen tension to inspired oxygen fraction $\left(\mathrm{PaO}_{2} / \mathrm{FiO}_{2}\right)$ ratio $<250 \mathrm{mmHg}$ during Venturi mask oxygen therapy [14]. Patients who received post-extubation CPAP/NPPV were excluded.

All hospital charts were reviewed for routinely collected patients' demographic and clinical features, including age, gender, smoking habits, body mass index (BMI), and comorbidities, likely to influence outcome measures, such as chronic obstructive pulmonary disease (COPD), asthma, diabetes mellitus, cardiac disease-i.e., cardiac arrhythmia, previ- 
ous myocardial infarction, angina pectoris, and/or congestive heart failure-and chronic renal failure. The Charlson comorbidity index score adjusted by age (ACCI) was also calculated for each patient [15].

On admission to the IRCU, the following parameters were recorded and analysed: time since onset of symptoms, Barthel index for activities of daily living [16] or Blaylock risk assessment screening score (BRASS) [17], respiratory rate (RR), heart rate (HR), body temperature, leukocyte count, $\mathrm{D}$-dimer, serum $\mathrm{C}$-reactive protein (CRP), arterial $\mathrm{PaO}_{2}, \mathrm{PaCO}_{2}$, and $\mathrm{pH}$ during spontaneous breathing with supplemental oxygen, and $\mathrm{PaO}_{2} / \mathrm{FiO}_{2}$. The sequential organ failure assessment (SOFA) score was also calculated [18]. According to the Barthel index score and BRASS, patients were considered at low (Barthel index $>80$ and/or BRASS $\leq 10$ ), moderate (Barthel index between 41 and 80 and/or BRASS between 11 and 19 ), or high (Barthel index $\leq 40$ and/or BRASS $\geq 20$ ) level of dependence, respectively [19].

\subsection{Interventions}

Details on CPAP/NPPV schedule, criteria for intubation, and IRCU organization are reported in the Supplementary Materials.

\subsection{Outcome Measures and Statistical Analysis}

Patients' outcomes based on vital status parameters at both hospital discharge and 90-day follow-up after hospital admission, the length of stay at IRCU and hospital, and non-invasive, invasive, and total duration of MV, were analysed.

Descriptive statistics were performed to summarise the patients' characteristics. Categorical variables were reported as absolute frequencies and percentages, whilst continuous variables were reported as median and first and third quartiles, as they were not found to be normally distributed. The Shapiro-Wilks test was used to assess whether or not continuous variables followed the normal distribution. Mann-Whitney and Chi square tests were used to assess the differences in patients' characteristics between the NIRS and NIRS+IMV group.

Univariable Cox proportional hazard models were used to calculate the hazard ratios (HRs) in order to evaluate a possible association between the patients' characteristics and the risk of death at 90 days. The Simon and Makuch's method was applied to draw survival curves stratified by treatment (NIRS vs. NIRS+IMV), accounting for the time-dependent nature of the stratification variable. The Mantel and Bayar test was used to assess the differences in survival curves Univariable and multivariable Cox proportional hazard models were used to analyse the relationship between treatment and 90-day mortality adjusted for selected confounders. A stepwise procedure was used to select the variables to be included in the multivariable model. As for survival curves, treatment was included in the model as time-dependent variable to avoid immortal time bias. All statistical analyses were conducted using SAS software for Windows, version 9.4 (SAS Institute, Cary, NC, USA).

\section{Results}

\subsection{Patient Characteristics}

During the study period, 252 patients aged $\geq 80$ years admitted to IRCUs for hARF with a primary diagnosis of COVID-19 severe pneumonia were prescribed NIRS, administered as CPAP/NPPV, and were included in our retrospective study. Among them, 228 $(90.5 \%)$ received CPAP/NPPV as the highest level of respiratory assistance (NIRS group), while $24(9.5 \%)$ received IMV via endotracheal intubation (ETI) after CPAP/NPPV failure (NIRS+IMV group).

The patients' baseline demographic and clinical characteristics and clinical and laboratory data on IRCU admission are outlined in Table 1 . When compared with NIRS+IMV patients, NIRS patients were on average two years older (84 vs. 82 years; $p=0.0183$ ), had higher $\mathrm{PaCO}_{2}$ (34 vs. $32 \mathrm{mmHg}, p=0.0449$ ) and lower serum CRP (11 vs. $15 \mathrm{mg} / \mathrm{dL}$; $p=0.0280)$ levels, and displayed a lower SOFA score (3 vs. $5 ; p=0.0338)$. 
Table 1. Patients' baseline demographic and clinical characteristics, clinical and laboratory data on Intermediate Respiratory Care Unit admission, and clinical outcomes.

\begin{tabular}{|c|c|c|c|c|}
\hline & Overall $(n=252)$ & NIRS $(n=228)$ & NIRS+IMV (n = 24) & $p$-Value \\
\hline \multicolumn{5}{|l|}{$\begin{array}{c}\text { Baseline demographic and clinical } \\
\text { data }\end{array}$} \\
\hline Age, years & $84(82-87)$ & $84(82-87)$ & $82(81-84)$ & 0.0183 \\
\hline Female, $\mathrm{n}$ & $92(37)$ & $86(38)$ & $6(25)$ & 0.2183 \\
\hline Non-smokers, $\mathrm{n}$ & $158(73)$ & $148(73)$ & $10(63)$ & $0.3867^{\wedge}$ \\
\hline \multicolumn{5}{|l|}{ Level of dependence } \\
\hline -low & $74(42)$ & $68(42)$ & $6(35)$ & \multirow{3}{*}{0.3167} \\
\hline -moderate & $27(15)$ & $26(16)$ & $1(6)$ & \\
\hline -high & $77(43)$ & $67(42)$ & $10(59)$ & \\
\hline Body mass index, $\mathrm{kg} / \mathrm{m}^{2}$ & $26(23-29)$ & $26(23-29)$ & $24(22-29)$ & 0.1536 \\
\hline ACCI & $6(4-7)$ & $6(4-7)$ & $6(4-8)$ & 0.7976 \\
\hline \multicolumn{5}{|l|}{$\begin{array}{l}\text { Clinical, laboratory and blood gas } \\
\text { data on IRCU admission }\end{array}$} \\
\hline Time since symptom onset, days & $5(3-8)$ & $5(3-8)$ & $6(3-10)$ & 0.6606 \\
\hline Heart rate, beats $/ \mathrm{min}$ & $83(74-95)$ & $82(74-95)$ & $85(75-94)$ & 0.7098 \\
\hline Respiratory rate, breaths/min & $26(22-30)$ & $26(22-30)$ & $25(18-27)$ & 0.0726 \\
\hline Temperature, Celsius & $36.5(36-37)$ & $36.5(36-37)$ & $36.8(36.7-37)$ & 0.1179 \\
\hline White blood cell count, $\times 10^{3} / \mu \mathrm{L}$ & $8.5(6.1-12.1)$ & $8.5(6.1-12.1)$ & $8.6(6.9-12.1)$ & 0.5512 \\
\hline D-dimer, $\mu \mathrm{gFEU} / \mathrm{L}$ & $628(238-1900)$ & $620(241-1691)$ & $1317(207-3180)$ & 0.2915 \\
\hline Serum C-reactive protein, $\mathrm{mg} / \mathrm{dL}$ & $11(6-16)$ & $11(6-15)$ & $15(10-25)$ & 0.0280 \\
\hline $\mathrm{PaO}_{2}, \mathrm{mmHg}$ & $56(45-69)$ & $56(46-69)$ & $53(41-73)$ & 0.4886 \\
\hline $\mathrm{PaCO}_{2} \mathrm{mmHg}$ & $34(30-38)$ & $34(31-38)$ & $32(28-37)$ & 0.0449 \\
\hline Arterial $\mathrm{pH}$ & $7.45(7.42-7.49)$ & $7.45(7.42-7.48)$ & $7.46(7.42-7.49)$ & 0.5132 \\
\hline $\mathrm{SaO}_{2}, \%$ & $89(82-93)$ & $89(83-93)$ & $86(76-95)$ & 0.3328 \\
\hline $\mathrm{PaO}_{2} / \mathrm{FiO}_{2}, \mathrm{mmHg}$ & $110(80-172)$ & $111(81-171)$ & $100(61-190)$ & 0.4361 \\
\hline SOFA score & $4(3-5)$ & $3(3-4)$ & $5(3-6)$ & 0.0338 \\
\hline \multicolumn{5}{|l|}{ Clinical outcomes } \\
\hline Days on mechanical ventilation & $6(3-10)$ & $6(2-10)$ & $8(6-13)$ & 0.0121 \\
\hline Days on non-invasive ventilation & $5(2-10)$ & $5(2-10)$ & $5(1-9)$ & 0.1870 \\
\hline Days on invasive ventilation * & NA & NA & $4(0-7)$ & NA \\
\hline Length of IRCU stay, days & $8(4-13)$ & $8(4-13)$ & $5(1-11)$ & 0.1126 \\
\hline Length of hospital stay, days & $14(8-23)$ & $14(8-23)$ & $18(11-26)$ & 0.1968 \\
\hline Pts discharged alive, $\mathrm{n}(\%)$ & $96(38)$ & $89(39)$ & $7(29)$ & 0.7636 \\
\hline Pts alive at 90-day follow-up, n (\%) & $89(35)$ & $83(36)$ & $6(25)$ & 0.3854 \\
\hline
\end{tabular}

Data are presented as median (interquartile range) or number (percentage), $P$-values refer to differences between "NIRS" and "NIRS+IMV". NIRS, non-invasive respiratory support; IMV, invasive mechanical ventilation; $\mathrm{ACCI}$, age adjusted Charlson comorbidity index; $\mathrm{PaO}_{2} / \mathrm{FiO}_{2}$, arterial partial pressure of oxygen to inspired oxygen fraction ratio; $\mathrm{SaO}_{2}$, arterial oxygen saturation; $\mathrm{SOFA}$, sequential organ failure assessment; NA, not applicable; IRCU, intermediate respiratory care unit. ^ Fisher exact test. * Calculated on patients undergoing endotracheal intubation.

\subsection{Clinical Outcomes}

Out of 252 study participants, 156 (61.9\%) and 163 (64.6\%) died during hospital stay and within 90 days from hospital admission, respectively. Among 228 patients in the NIRS group, $139(61.0 \%)$ died during hospital stay, while $145(63.6 \%)$ were deceased at 90-day follow-up. Out of 24 patients in the NIRS+IMV group, $17(70.8 \%)$ and $18(75 \%)$ died during hospital stay and within 90 days from hospitalization, respectively. The proportion of deaths during hospitalization and at 90-day follow-up were not significantly different between NIRS and NIRS+IMV group ( $p=0.507$ and $p=0.3697$, respectively). Data on patient clinical course are illustrated in Figure 1. 


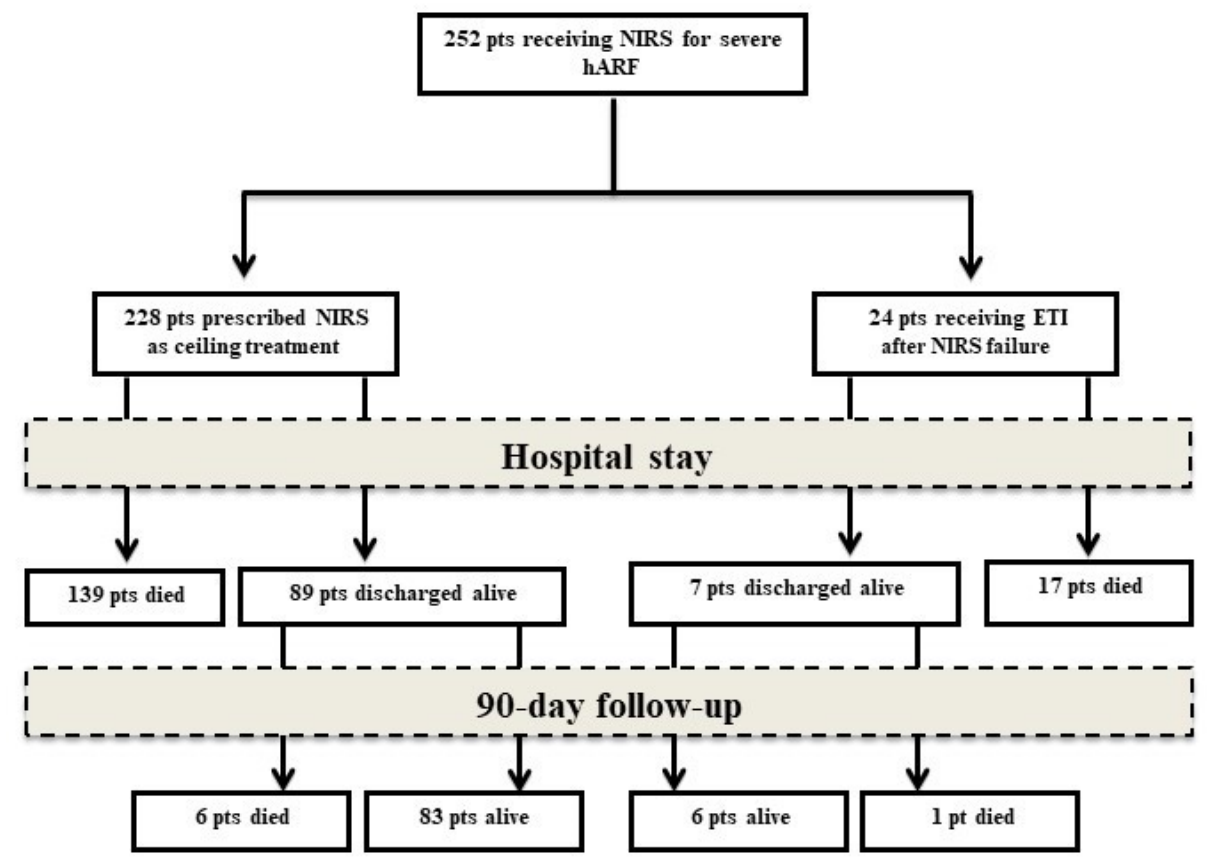

Figure 1. Study profile. NIRS, non-invasive respiratory support; ETI, endotracheal intubation.

Table 2 outlines the HRs for the association between the patients' characteristics and the risk of 90-day mortality according to univariable Cox models. Older age, increasing CRP, SOFA score, and level of dependence were all associated with a statistically significant increased risk of death at 90 days, whilst higher levels of $\mathrm{SaO}_{2}$ and longer duration of MV were associated with a decreased risk of death.

Table 2. Distribution of patient characteristics according to death status at 90 days after hospitalization and hazard ratio (HR) and 95\% confidence interval $(95 \% \mathrm{CI})$ derived from the univariable Cox proportional hazard model.

\begin{tabular}{|c|c|c|c|c|}
\hline \multicolumn{5}{|c|}{ Deceased at 90-Day Follow-Up } \\
\hline & No $(n=89)$ & Yes $(n=163)$ & All $(n=252)$ & HR $(95 \% C I)$ \\
\hline Age, years & $83(81-85)$ & $85(82-87)$ & $84(82-87)$ & $1.064(1.022-1.107)$ \\
\hline Female (M/F), \% & $33(37)$ & $59(36)$ & $92(37)$ & $1.097(0.797-1.510)$ \\
\hline Non-smokers, $\mathrm{n}$ & $58(70)$ & $100(74)$ & $158(73)$ & 1 \\
\hline \multicolumn{5}{|l|}{ Level of dependence, $\mathrm{n}$} \\
\hline -low & $39(57)$ & $35(32)$ & $74(42)$ & 1 \\
\hline -moderate & $14(21)$ & $13(12)$ & $27(15)$ & $1.020(0.540-1.927)$ \\
\hline -high & $15(22)$ & $62(56)$ & $77(43)$ & $2.217(1.462-3.362)$ \\
\hline Body mass index, $\mathrm{kg} / \mathrm{m}^{2}$ & $26(23-29)$ & $26(24-29)$ & $26(23-29)$ & $0.980(0.930-1.033)$ \\
\hline ACCI & $5(4-7)$ & $6(4-7)$ & $6(4-7)$ & $1.053(0.995-1.114)$ \\
\hline Time since symptom onset, days & $5(3-10)$ & $5(3-8)$ & $5(3-8)$ & $0.979(0.945-1.014)$ \\
\hline Heart rate, beats $/ \mathrm{min}$ & $80(74-94)$ & $83(74-98)$ & $83(74-95)$ & $1.008(0.998-1.018)$ \\
\hline Respiratory rate, breaths/min & $26(22-30)$ & $26(22-30)$ & $26(22-30)$ & $1.015(0.988-1.043)$ \\
\hline Temperature, Celsius & $36.5(36-37)$ & $36.5(36-37)$ & $36.5(36-37)$ & $1.097(0.833-1.446)$ \\
\hline White blood cell count, $\times 10^{3} / \mu \mathrm{L}$ & $8.24(6.13-11)$ & $8.79(6.17-12.64)$ & $8.5(6.13-12.1)$ & $1.006(0.979-1.035)$ \\
\hline D-dimer, $\mu \mathrm{gFEU} / \mathrm{L}$ & $524(198-1544)$ & $711(241-2356)$ & $628(238-1900)$ & $1.000(1.000-1.000)$ \\
\hline Serum C-reactive protein, $\mathrm{mg} / \mathrm{dL}$ & $9.59(5.3-14.76)$ & $11.44(7.01-16.9)$ & $11(6.36-15.9)$ & $1.037(1.016-1.059)$ \\
\hline $\mathrm{PaO}_{2}, \mathrm{mmHg}$ & $59(47-75)$ & $53(44-67)$ & $56(45-69)$ & $0.992(0.984-1.000)$ \\
\hline $\mathrm{PaCO}_{2} \mathrm{mmHg}$ & $35(31-38)$ & $33(30-37)$ & $34(30-38)$ & $0.992(0.973-1.011)$ \\
\hline Arterial $\mathrm{pH}$ & $7.46(7.42-7.49)$ & $7.45(7.41-7.48)$ & $7.45(7.42-7.49)$ & $0.463(0.053-4.045)$ \\
\hline $\mathrm{SaO}_{2}, \%$ & $90(84-94)$ & $88(82-93)$ & $89(82-93)$ & $0.975(0.959-0.992)$ \\
\hline
\end{tabular}


Table 2. Cont.

\begin{tabular}{|c|c|c|c|c|}
\hline \multicolumn{5}{|c|}{ Deceased at 90-Day Follow-Up } \\
\hline & No $(n=89)$ & Yes $(n=163)$ & All $(n=252)$ & HR $(95 \% C I)$ \\
\hline $\mathrm{PaO}_{2} / \mathrm{FiO}_{2}, \mathrm{mmHg}$ & $120(88-179)$ & $104(76-170)$ & $110(79-172)$ & $0.998(0.995-1.001)$ \\
\hline SOFA score & $3(2-4)$ & $4(3-5)$ & $4(3-5)$ & $1.195(1.111-1.285)$ \\
\hline Days on mechanical ventilation & $7(3-12)$ & $5(2-8.5)$ & $6(3-10)$ & $0.946(0.919-0.974)$ \\
\hline
\end{tabular}

ACCI, age-adjusted Charlson comorbidity index; $\mathrm{HR}$, hazard ratio; $\mathrm{PaO}_{2}$, arterial partial pressure of oxygen $\mathrm{PaCO}_{2}$, arterial partial pressure of carbon dioxide; $\mathrm{PaO}_{2} / \mathrm{FiO}_{2}$, arterial partial pressure of oxygen to inspired oxygen fraction ratio; $\mathrm{SaO}_{2}$, arterial oxygen saturation; SOFA, sequential organ failure assessment.

Figure 2 shows Simon and Makuch's curves stratified by treatment. The median survival time was 22 (9.0-NA) days for patients in the NIRS group and 12 (8.0-21.0) days for those in the NIRS+IMV group.. Furthermore, the survival probability at 90 days of NIRS and NIRS+IMV patients was 0.379 (risk of death: 0.621) and 0.147 (risk of death: $0.835)$, respectively. According to the Mantel and Bayar's test, the curves were significantly different $(p=0.0025)$. Although NIRS+IMV patients showed a risk of dying at 90-day follow-up 2.18 times higher $(95 \%$ CI 1.33-3.56) than that observed in patients only treated with NIRS, this increased risk failed to reach a statistically significant level after adjustment for age, ACCI, CRP, SOFA score, and $\mathrm{SaO}_{2}$ (Table 3).

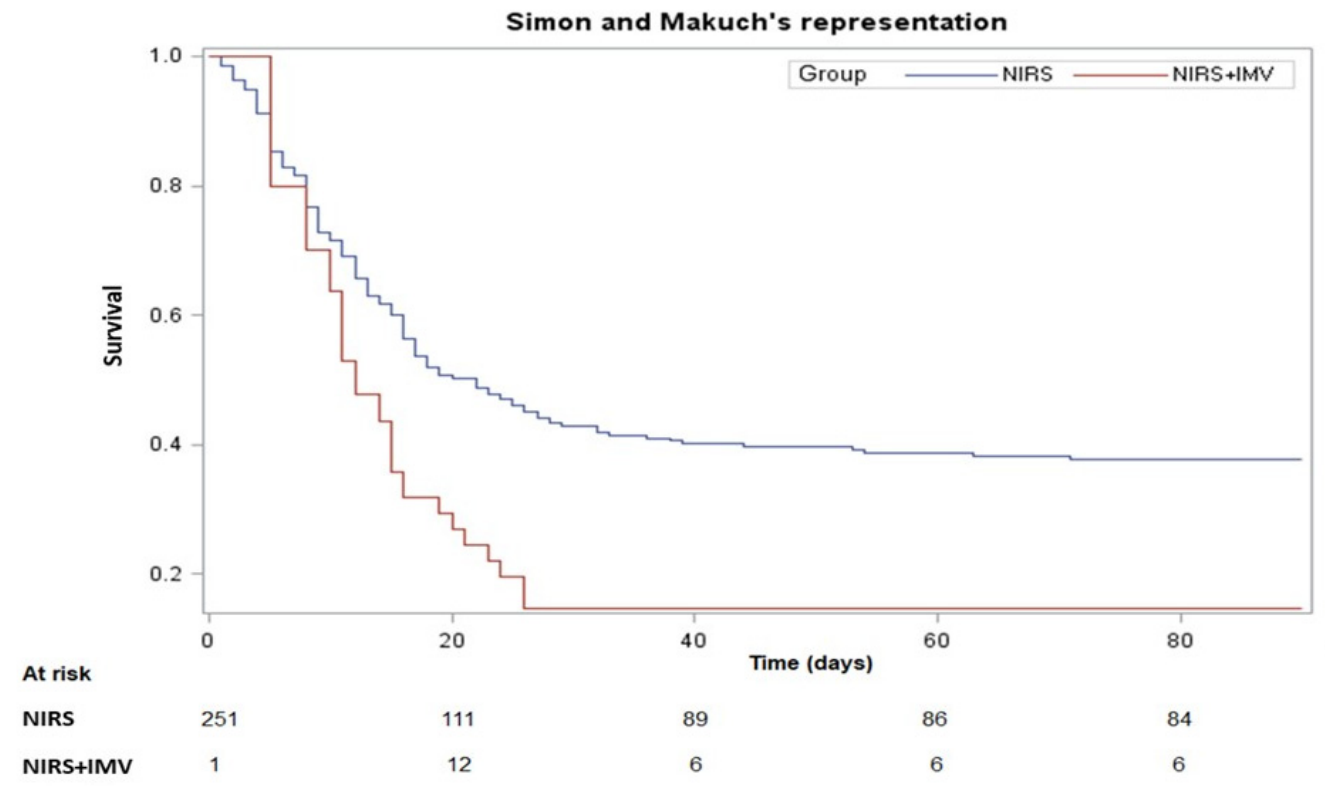

Figure 2. Simon and Makuch's survival curves stratified by treatment.

Table 3. Hazard ratios (HRs) for the association between ventilatory treatment and the risk of 90-day mortality according to univariable and multivariable Cox proportional hazard models.

\begin{tabular}{ccc}
\hline & $\begin{array}{c}\text { Univariable Model } \\
\text { HR (95\% CI) }\end{array}$ & $\begin{array}{c}\text { Multivariable Model } \\
\text { HR (95\% CI) }\end{array}$ \\
\hline NIRS+IMV vs. NIRS & $2.17(1.33-3.56)$ & $1.76(0.86-3.60)$ \\
\hline Age & $1.11(1.05-1.17)$ \\
\hline ACCI & $1.11(1.03-1.18)$ \\
\hline CRP & $1.05(1.02-1.07)$ \\
\hline SOFA score & $1.16(1.06-1.26)$ \\
\hline $\mathrm{SaO}_{2}$ & $0.97(0.95-0.99)$ \\
\hline
\end{tabular}

NIRS, non-invasive respiratory support; IMV, invasive mechanical ventilation; ACCI, age-adjusted Charlson comorbidity index; CRP, C-reactive protein; $\mathrm{SOFA}$, sequential organ failure assessment; $\mathrm{SaO}_{2}$, arterial oxygen saturation; $\mathrm{HR}$, hazard ratio; $\mathrm{CI}$, confidence interval. 
The total duration of MV was significantly longer in the NIRS+IMV group compared to the NIRS group ( 8 vs. 6 days, $p=0.0121$ ). The time spent on NIRS was similar between the two groups, with a median time of 5 days; the median duration of IMV in the NIRS+IMV group was 4 (0-7) days.

\section{Discussion}

The present study shows that both in-hospital and 90-day follow-up mortality rates were above $60 \%$ (61.9\% and $64.6 \%$, respectively) in a large cohort of octogenarians receiving NIRS for COVID-19 hARF. Moreover, patients undergoing IMV after NIRS failure, representing $9.5 \%$ of our study population, had a significantly lower survival probability at 90 days than that of patients receiving NIRS as a ceiling of care. After adjusting mortality for age, ACCI, CRP, SOFA score, and $\mathrm{SaO}_{2}$, no additional benefit in terms of survival was found for patients in the NIRS+IMV group.

Recently, a number of studies have focussed on the mortality risk of older patients hospitalised for COVID-19-related ARF, showing that $40 \%$ of octogenarians admitted to hospital for COVID-19 pneumonia did not survive at 28-day from hospital admission [20], and that the mortality rate increased up to $50 \%$ among patients receiving out-of-ICU NIRS [8]. Moreover, case fatality rate of patients aged 80 years or older admitted to ICU for COVID-19-associated ARDS was as high as $84 \%$ [21], which is a much higher value than that of same age patients with non-COVID-19-related ARDS requiring planned or unplanned ICU admission [22,23]. Furthermore, Lim et al., reported that COVID-19 octogenarian patients undergoing IMV have a higher mortality rate compared to patients of similar age admitted to ICU and treated with NIRS [21].

An association between increasing age and higher NIRS failure rate was reported by several observational studies [24-26]. In particular, a prospective cohort study on patients undergoing NIRS due to de novo hypoxemic ARF showed that patients aged $\geq 80$ years had much higher ICU and hospital mortality rates than those of patients aged $<80$ years ( $28 \%$ vs. $17 \%, p=0.03$, and $40 \%$ vs. $25 \%, p<0.01$, respectively), with the highest values recorded in the 'do-not-intubate' (DNI) subgroup [27]. This led the authors to recommend caution when considering NIRS in very old patients. In contrast, a subsequent retrospective, observational study on patients undergoing NIRS to treat ARF of various aetiologies (i.e., COPD exacerbation, acute pulmonary oedema, sepsis, and pneumonia) [28] showed that the in-hospital mortality rate of very old individuals ( $\geq 85$ years) was comparable to that observed in younger patients, despite a higher predicted mortality in the former population. We believe that these contrasting observations may be attributable to the fact that NIRS outcomes in old age patients can be heavily influenced by the baseline disease, with hypoxemic ARF being the least responsive to treatment [28].

Given the high NIRS failure rate and the overall poor survival rate in patients aged $\geq 80$ years, the identification and implementation of appropriate selection criteria for potential NIRS candidates would allow the development of a proper strategy for allocation of IRCU resources during a pandemic. In this regard, when patient characteristics associated with NIRS failure were analysed, we found that increased CRP, SOFA, and ACCI values were associated with a statistically significant higher risk of death at 90 days. Whilst these parameters have been reported to be sensitive prognostic indicators of in-hospital mortality in a population of COVID-19 patients distributed over a wide age range [11,29-31], to our knowledge this is the first study showing their importance in predicting a successful outcome of NIRS among patients aged 80 year or older. Moreover, in our patients the level of dependence on IRCU admission appears to be significantly associated with the risk of mortality. Indeed, patients with increased levels of frailty (Barthel index $\leq 40$ and/or BRASS $\geq 20$ ) had a substantially higher risk of mortality (over 2-fold) compared to that of patients with a low and/or moderate dependence level. In good agreement, a retrospective study on a group of 100 very old COVID-19 cases (median age: 85 years) in a long-term care setting revealed a strong correlation between Barthel index and mortality [32]. 
The decision to offer IMV to very old patients responding poorly to NIRS is still largely debated. In our study, 9.5\% patients were switched to IMV after experiencing NIRS failure: they were found to be slightly younger, had a significantly higher SOFA score, and showed slightly higher CRP values compared to patients who were not intubated. Of note, the clinical outcomes of patients undergoing IMV were basically the same as those of the NIRS group. Our findings are in line with those reported by a prospective cohort study of Schortgen et al., that examined 163 very old patients admitted to Intensive Care Unit (ICU) who received non-invasive ventilation (NIV) for standard indications (i.e., chronic obstructive pulmonary disease (COPD) exacerbation and/or cardiogenic pulmonary oedema), demonstrating that the 6-month mortality rate was $67 \%$ for DNI patients increasing to $77 \%$ in patients switched to IMV following NIRS failure [27]. Indeed, Lerolle et al., claimed that complications occurring during IMV in older patients ( $\geq 80$ years), reflecting frailty of old age and multiple comorbidities, may explain why the risk of hospital mortality is increased in very old individuals undergoing invasive ventilatory treatment [33].

Being retrospective and observational, our study has some limitations (e.g., unknown confounding factors, selection bias etc.), which would have been avoided by performing a prospective analysis. It should be however considered that prospective randomized trials are unlikely to be conducted in a pandemic scenario such as the one we have been experiencing in the last two years. In addition, because of our study design, we must admit that our findings may not be extended to other conditions due to the exceptionality of the COVID-19 pandemic outbreak. Furthermore, as our study is based on NIRS techniques implemented at IRCUs, our results cannot be applied to same age patients managed in the ward. Finally, the decision of excluding DNI patients from intubation and therapeutic up-grade was not based on standardized protocols but rather on clinical judgment.

\section{Conclusions}

The clinical outcome of patients aged 80 years or older with COVID-19-associated ARF receiving NIRS at IRCUs is very poor, and increased levels of frailty on IRCU admission are associated with an even poorer prognosis. Given the extremely poor prognosis of patients intubated after NIRS failure, caution should be used when considering seriously ill older adults for IMV after unsuccessful NIRS.

Altogether, our results may favour a more efficient use of IRCU resources during future COVID-19 outbreaks, particularly in settings where the availability of clinicians, beds and equipment is limited.

Supplementary Materials: The following supporting information can be downloaded at: https:/ / www.mdpi.com/article/10.3390/jcm11051372/s1, Text file including details on ventilatory treatment and intermediate respiratory care unit organization.

Author Contributions: Conceptualization: P.N.; formal analysis: L.S.; investigation: G.G., V.B., C.M., G.A. (Gianluca Airoldi), C.O., P.P.S., F.L., G.A. (Giovanna Arcaro) and F.D.C.; data curation: B.M. and N.D.V.; supervision: M.C.; writing—original draft: R.V.; writing—review and editing: A.V. All authors have read and agreed to the published version of the manuscript.

Funding: RV was supported by funding from the University of Piemonte Orientale, AGING ProjectDepartment of Excellence-DIMET.

Institutional Review Board Statement: Participating centres obtained ethics committee approval for the present research project (CE 243/21).

Informed Consent Statement: Due to the retrospective nature of the study, the ethics committee waived the need for informed consent.

Data Availability Statement: The data that support the findings of this study are available from the corresponding author, [A.V.], upon reasonable request. 
Conflicts of Interest: P.N. reports, outside the submitted work, personal fees from Intersurgical SpA, Resmed, Philips, MSD, Getinge and Gilead. He is recipients of a research grant and nonfinancial support from Draeger, and of a research grant from Gilead. In addition, P.N. has a patent 102020000008305 pending to Università di Padova, and a patent 102016000114357 with royalties paid by Intersurgical S.p.A. A.V. reports personal fees from Menarini and CSL Behring, and nonfinancial support from Philips, outside the submitted work. R.V. received honorarium for lecture from Intersurgical (2021). The other authors received no financial support for the research, authorship, and/or publication of this article.

\section{References}

1. Zhou, F.; Yu, T.; Du, R.; Fan, G.; Liu, Y.; Liu, Z.; Xiang, J.; Wang, Y.; Song, B.; Gu, X.; et al. Clinical course and risk factors for mortality of adult inpatients with COVID-19 in Wuhan, China: A retrospective cohort study. Lancet 2020, 395, $1054-1062$. [CrossRef]

2. Livingston, E.; Bucher, K. Coronavirus Disease 2019 (COVID-19) in Italy. JAMA 2020, 323, 1335. [CrossRef] [PubMed]

3. Onder, G.; Rezza, G.; Brusaferro, S. Case-fatality rate and characteristics of patients dying in relation to COVID-19 in Italy. JAMA 2020, 323, 1775-1776. [CrossRef] [PubMed]

4. Richardson, S.; Hirsch, J.S.; Narasimhan, M.; Crawford, J.M.; McGinn, T.; Davidson, K.W.; the Northwell COVID-19 Research Consortium. Presenting characteristics, comorbidities, and outcomes among 5700 patients hospitalized with COVID-19 in the New York City area. JAMA 2020, 323, 2052-2059. [CrossRef]

5. Capdevila-Reniu, A.; Pellice, M.; Prieto-Gonzalez, S.; Ventosa, H.; Ladino, A.; Naval, J.; Rodriguez-Nuñez, O.; César Milisenda, J.; Moreno-Lozano, P.J.; Soriano, A.; et al. Clinical characteristics and outcome of patients aged over 80 years with COVID-19. Medicine 2021, 100, e24750. [CrossRef] [PubMed]

6. Jung, C.; Flaatten, H.; Fjølner, J.; Bruno, R.R.; Wernly, B.; Artigas, A.; Pinto, B.B.; Schefold, J.C.; Wolff, G.; Kelm, M.; et al. The impact of frailty on survival in elderly intensive care patients with COVID-19: The COVIP study. Crit. Care 2021, 25, 149. [CrossRef]

7. Karagiannidis, C.; Mostert, C.; Hentschker, C.; Voshaar, T.; Malzahn, J.; Schillinger, G.; Klauber, J.; Janssens, U.; Marx, G.; Weber-Carstens, S.; et al. Case characteristics, resource use, and outcomes of 10021 patients with COVID-19 admitted to 920 German hospitals: An observational study. Lancet Respir. Med. 2020, 8, 853-862. [CrossRef]

8. Aziz, S.; Arabi, Y.M.; Alhazzani, W.; Evans, L.; Citerio, G.; Fischkoff, K.; Salluh, J.; Meyfroidt, G.; Alshamsi, F.; Oczkowski, S.; et al. Managing ICU surge during the COVID-19 crisis: Rapid guidelines. Intensiv. Care Med. 2020, 46, 1303-1325. [CrossRef]

9. Franco, C.; Facciolongo, N.; Tonelli, R.; Dongilli, R.; Vianello, A.; Pisani, L.; Scala, R.; Malerba, M.; Carlucci, A.; Negri, E.A.; et al. Feasibility and clinical impact of out-of-ICU noninvasive respiratory support in patients with COVID-19-related pneumonia. Eur. Respir. J. 2020, 56, 2002130. [CrossRef]

10. Aliberti, S.; Radovanovic, D.; Billi, F.; Sotgiu, G.; Costanzo, M.; Pilocane, T.; Saderi, L.; Gramegna, A.; Rovellini, A.; Perotto, L.; et al. Helmet CPAP treatment in patients with COVID-19 pneumonia: A multicentre cohort study. Eur. Respir. J. 2020, $56,2001935$. [CrossRef]

11. Vaschetto, R.; Barone-Adesi, F.; Racca, F.; Pissaia, C.; Maestrone, C.; Colombo, D.; Olivieri, C.; Vita, N.D.; Santangelo, E.; Scotti, L.; et al. Outcomes of COVID-19 patients treated with continuous positive airway pressure outside the intensive care unit. ERJ Open Res. 2021, 7, 00541-2020. [CrossRef] [PubMed]

12. Walker, J.; Dolly, S.; Ng, L.; Prior-Ong, M.; Sabapathy, K. The role of CPAP as a potential bridge to invasive ventilation and as a ceiling-of-care for patients hospitalized with COVID-19-An observational study. PLoS ONE 2020, 15, e0244857. [CrossRef] [PubMed]

13. World Health Organization. Clinical Management of Severe Acute Respiratory Infection (SARI) When COVID-19 Disease Is Suspected: Interim Guidance; World Health Organization: Geneva, Switzerland, 13 March 2020.

14. Gungor, G.; Tatar, D.; Salturk, C.; Çimen, P.; Karakurt, Z.; Kirakli, C.; Adıgüzel, N.; Ediboğlu, Ö.; Yılmaz, H.; Moçin, Ö.Y.; et al. Why do patients with interstitial lung diseases fail in the ICU? A 2-center cohort study. Respir. Care 2013, 58, 525-531. [CrossRef]

15. Charlson, M.E.; Pompei, P.; Ales, K.L.; MacKenzie, C.R. A new method of classifying prognostic comorbidity in longitudinal studies: Development and validation. J. Chronic Dis. 1987, 40, 373-383. [CrossRef]

16. Mahoney, F.I.; Barthel, D.W. Functional evaluation: The Barthel Index. Md. State Med. J. 1965, 14, 61-65.

17. Blaylock, A.; Cason, C.L. Discharge planning predicting patients' needs. J. Gerontol. Nurs. 1992, 18, 5-10. [CrossRef] [PubMed]

18. Vincent, J.L.; De Mendonça, A.; Cantraine, F.; Moreno, R.; Takala, J.; Suter, P.M.; Sprung, C.L.; Colardyn, F.; Blecher, S. Use of the SOFA score to assess the incidence of organ dysfunction/failure in intensive care units: Results of a multicenter, prospective study. Working group on "sepsis-related problems" of the European Society of Intensive Care Medicine. Crit. Care Med. 1998, 26, 1793-1800. [CrossRef]

19. Strini, V.; Piazzetta, N.; Gallo, A.; Schiavolin, R. Barthel Index: Creation and validation of two cut-offs using the BRASS Index. Acta Biomed. 2020, 91, 19-26.

20. Hewitt, J.; Carter, B.; Vilches-Moraga, A.; Quinn, T.J.; Braude, P.; Verduri, A.; Pearce, L.; Stechman, M.; Short, R.; Price, A.; et al. The effect of frailty on survival in patients with COVID-19 (COPE): A multicentre, European, observational cohort study. Lancet Public Health 2020, 5, e444-e451. [CrossRef] 
21. Lim, Z.J.; Subramaniam, A.; Ponnapa, R.M.; Blecher, G.; Kadam, U.; Afroz, A.; Billah, B.; Ashwin, S.; Kubicki, M.; Bilotta, F.; et al. Case fatality rates for patients with COVID-19 requiring invasive mechanical ventilation. A meta-analysis. Am. J. Respir. Crit. Care Med. 2021, 203, 54-66. [CrossRef]

22. Guidet, B.; De Lange, D.W.; Boumendil, A.; Leaver, S.; Watson, X.; Boulanger, C.; Szczeklik, W.; Artigas, A.; Morandi, A.; Andersen, F.; et al. The contribution of frailty, cognition, activity of daily life and comorbidities on outcome in acutely admitted patients over 80 years in European ICUs: The VIP2 study. Intensive Care Med. 2020, 46, 57-69. [CrossRef] [PubMed]

23. Flaatten, H.; De Lange, D.W.; Morandi, A.; Andersen, F.H.; Artigas, A.; Bertolini, G.; Boumendil, A.; Cecconi, M.; Christensen, S.; Faraldi, L.; et al. The impact of frailty on ICU and 30-day mortality and the level of care in very elderly patients (>/=80 years). Intensive Care Med. 2017, 43, 1820-1828. [CrossRef] [PubMed]

24. Coppadoro, A.; Benini, A.; Fruscio, R.; Verga, L.; Mazzola, P.; Bellelli, G.; Carbone, M.; Mulinacci, G.; Soria, A.; Noè, B.; et al. Helmet CPAP to treat hypoxic pneumonia outside the ICU: An observational study during the COVID-19 outbreak. Crit. Care 2021, 25, 80. [CrossRef] [PubMed]

25. Avdeev, S.N.; Yaroshetskiy, A.I.; Tsareva, N.A.; Merzhoeva, Z.M.; Trushenko, N.V.; Nekludova, G.V.; Chikina, S.Y. Noninvasive ventilation for acute hypoxemic respiratory failure in patients with COVID-19. Am. J. Emerg. Med. 2021, 39, 154-157. [CrossRef] [PubMed]

26. Bellani, G.; Grasselli, G.; Cecconi, M.; Antolini, L.; Borelli, M.; De Giacomi, F.; Bosio, G.; Latronico, N.; Filippini, M.; Gemma, M.; et al. Noninvasive ventilatory support of COVID-19 patients outside the intensive care units (WARd-COVID). Ann. Am. Thorac. Soc. 2021, 18, 1020-1026. [CrossRef] [PubMed]

27. Schortgen, F.; Follin, A.; Piccari, L.; Roche-Campo, F.; Carteaux, G.; Taillandier-Heriche, E.; Krypciak, S.; Thille, A.W.; Paillaud, E.; Brochard, L. Results of noninvasive ventilation in very old patients. Ann Intensive Care 2012, 2, 5. [CrossRef]

28. Montoneri, G.; Noto, P.; Trovato, F.M.; Mangano, G.; Malatino, L.; Carpinteri, G. Outcomes of non-invasive ventilation in 'very old' patients with acute respiratory failure: A retrospective study. Emerg. Med. J. 2019, 36, 303-305. [CrossRef]

29. Liu, S.; Yao, N.; Qiu, Y.; He, C. Predictive performance of SOFA and qSOFA for in-hospital mortality in severe novel coronavirus disease. Am. J. Emerg. Med. 2020, 38, 2074-2080. [CrossRef]

30. Sharifpour, M.; Rangaraju, S.; Liu, M.; Alabyad, D.; Nahab, F.B.; Creel-Bulos, C.M.; Jabaley, C.S.; on behalf of the Emory COVID-19 Quality; Clinical Research Collaborative. C-Reactive protein as a prognostic indicator in hospitalized patients with COVID-19. PLoS ONE 2020, 15, e0242400. [CrossRef]

31. Imam, Z.; Odish, F.; Gill, I.; O'Connor, D.; Armstrong, J.; Vanood, A.; Ibironke, O.; Hanna, A.; Ranski, A.; Halalau, A. Older age and comorbidity are independent mortality predictors in a large cohort of 1305 COVID-19 patients in Michigan, United States. J. Intern. Med. 2020, 288, 469-476. [CrossRef]

32. Heras, E.; Garibaldi, P.; Boix, M.; Valero, O.; Castillo, J.; Curbelo, Y.; Gonzalez, E.; Mendoza, O.; Anglada, M.; Miralles, J.C.; et al. COVID-19 mortality risk factors in older people in a long-term care center. Eur. Geriatr. Med. 2021, 12, 601-607. [CrossRef] [PubMed]

33. Lerolle, N.; Trinquart, L.; Bornstain, C.; Tadié, J.M.; Imbert, A.; Diehl, J.L.; Fagon, J.-Y.; Guérot, E. Increased intensity of treatment and decreased mortality in elderly patients in an intensive care unit over a decade. Crit. Care Med. 2010, 38, 59-64. [CrossRef] [PubMed] 